\title{
ART CLUSTERS AND SQUATS AS HETEROTOPIAS OF THE CITY'S PUBLIC SPACE
}

\author{
Sofia Shkoliar ${ }^{1}$, Mariana Shkoliar ${ }^{2}$ \\ Lviv Polytechnic National University, Lviv, Ukraine \\ ${ }^{1}$ master student of the Architectural Design Department of Lviv Polytechnic National University \\ ${ }^{2}$ associate Professor of the Sociology and Social Work Department of Lviv Polytechnic National \\ University
}

Background: The existence of either an individual or particular social community cannot be imagined and understood beyond the space-time dimension. While considering space in sociological sense, it is possible to outline its various dimensions: physical, social, life, social, public, etc. As for the public space of the city, it should be noted that in the Western tradition it is accepted to use the term "public space", while domestic sociologists use a number of terms - "social space", "public space", "community space" etc. Talking about public space we mean accessible space - places for all, or for groups of people based on social freedom of movement and anonymity. This kind of public space definition underlies our interpretation of urban public art spaces forms, such as art clusters and squats, which exemplify the tendency of transforming individual urban areas into specific venues for communication of different fields of art, while involving the public in artistic and cultural processes.

Purpose: to analyze the essence of art clusters and squats as new forms of urban artistic public spaces, using M. Foucault's methodology of heterotopy.

Methods: The field of space exploration is quite broad, however, in the publication we will discourse on certain forms of urban art public spaces, in particular art clusters and squats, through the lens of Michel Foucault's heterotopy methodology (Foucault, 1994). Heterotopia is able to show social and informational interactions between people, its analysis opens the possibility of a more detailed study of locations in cultural and social spaces. So, heterotopy is a space that reflects cultural, political, social, artistic interaction and structures society through images.

Results: By term heterotopia, Foucault understands the space outside of other spaces, where rules and laws, which are familiar to the subject, and behavioral stereotypes undergo significant changes. A person who is in heterotopia needs to adapt for the new conditions and, in one way or another, to perform the act of transgression, which means to transcend the traditional behavior. M. Foucault has classified the whole spectrum of urban spaces, which in some way stand out from the overall urban picture. The first is heterotopia of crisis - certain places targeted at people who are in crisis relative to the society in which they live (elderly people, adolescents, etc.).The second is heterotopia of deviation, which refers to spaces for people whose behavior is considered to be deviant with respect to conventional. The third type of heterotopia, which M. Foucault did not outline as clearly as the previous two, is heterotopia of illusion, which combines the material and the intangible, the fictional and the real - museums, cinemas, entertainment centers and more. This type of heterotopia is a characteristic feature of the end of the industrial era and an indispensable attribute of post-industrial society. While considering current trends in the development of urban public art spaces, exhibition pavilions and art centers, we can see, that they have given their places for art clusters - revitalized industrial structures adapted to the functioning of various artistic practices. An art cluster is a cultural association located in the former industrial zone, which includes exhibition space, a theater and movie theater, seminar rooms, food courts and other similar elements. Art clusters or Lofts are the most widespread forms of creative space organization in the former factories. Industrial zones eventually ceased to function and became the focus of representatives of the creative professions, informal organizations and representatives of various deviant cultures. Clusters can be considered as positive spaces, as art clusters combine as a synthetic phenomenon both free creative search for artists and solving social problems. The revitalized space is created as a place aimed at the future: here contemporary art finds its territory and develops a new industrial scale. Squatting is the process of the unauthorized resettlement of abandoned or uninhabited premises by people who are not tenants or legal owners of the property. According to the classification of the Dutch sociologist G. Pryt, one of the squatting types is the "socio-cultural center" - it can be a bar, a workshop area, an art studio, a restaurant, an art gallery, a spiritual center and more. In this case, abandoned homes become squats 
to avoid serious financial investment and bureaucratic procedures. Many of these squats may later gain legal status, but they are primarily formed virtually illegally, in violation of social rules. Such newly created artistic public spaces can be interpreted as an example of heterotopy of deviance. In most of cases, the sociocultural dominance of squatters is the development in their space creative initiative, which leads to the formation of new cultural (often counter-cultural) spaces within the activity of squatters.

Conclusion: We can conclude that the places of contemporary art concentration, which we considered on the example of art clusters, according to M. Foucault, are positive expanses of time flow, or, in other words, heterotopias of fragile properties of time, where an alternative future is being developed. If we consider deviant art formations, such as art squats, through the lens of heterotopy theory, then they can be attributed to heterotopias of deviance, because in most cases, such formations are places of marginal artistic practices concentration. It should also be noted that in the modern age of digitization, art venues are heterotopias of illusion, since with the advent of new forms of visual art, in particular, of media art, such spaces become spaces of virtual reality.

Keywords: public space, heterotopia, heterotopia of crisis, heterotopia of deviation, heterotopia of illusion, art-cluster, squat, squatting.

Актуальність. Існування як окремої людини, так і певної соціальної спільноти неможливо уявити та зрозуміти поза просторово-часовим виміром. В сучасну епоху швидкості та стрімкого розвитку проблема плинності часу $є$ надзвичайно актуальною. Одночасно світ сьогодні демонструє себе не просто як життєвий процес, що відбувається у часі, а, радше, як «мережа, що з'єднує точки і сплітається у клубок» (Foucault, 1994), тобто час постає лише одним з існуючих способів розподілу складових у просторі.

Розглядаючи простір у соціологічному розумінні, можна окреслити різні його виміри: фізичний, соціальний, життєвий, суспільний, публічний тощо. Щодо суспільного простору міста, слід зазначити, що у західній традиції прийнято вживати термін «public space», тоді як вітчизняні соціологи використовують низку термінів - «суспільний простір», «публічний простір», «громадський простір» тощо. Поняття «public space» у сучасній європейській традиції розглядається в трьох основних аспектах: 1) як відкритий простір для відпочинку, рекреації, охорони здоров'я; 2) простір дебатів; 3) доступний простір - місця для всіх, або групи осіб, що грунтуються на основі соціальної свободи пересування та анонімності. (Жулькевська, .Грищенко ,2012). Саме третій аспект розуміння зазначеного поняття лежить в основі трактування нами таких форм міських суспільних мистецьких просторів, як арткластери та сквоти, які $є$ прикладом втілення тенденції перетворення окремих міських територій на специфічні майданчики для спілкування представників різних сфер мистецтва із залученням громадськості до художніх та культурних процесів.

Мета: розглянути сутність арт-кластерів і сквотів як нових форм міських мистецьких суспільних просторів, застосовуючи методологію гетеротопії М.Фуко.

Методологія. Поле дослідження простору є досить широким, однак в публікації проведемо дискурс певних форм міських мистецьких суспільних просторів, зокрема арт-кластерів та сквотів, крізь призму методології гетеротопії Мішеля Фуко (Foucault, 1994). На думку М.Фуко, життя особи великою мірою визначається переліком протиставлень, зокрема, - приватного i суспільного простору, простору сім’ї і соціального простору, простору відпочинку та простору праці тощо. Ці простори є не просто орієнтирами, якими може бути місцезнаходження індивіда, а складною системою взаємодій. Особливо М.Фуко цікавлять такі місця, які співвідносяться 3 іншими особливим чином, а саме: «призупиняють, нейтралізують чи перевертають усю сукупність відносин, які одночасно ними визначаються і відображаються» (Фуко, 2006). Особливість такого простору полягає в тому, що він знаходиться у взаємозв'язку 3 усіма іншими, але при цьому суперечить їм. Власне цей тип простору М. Фуко називає гетеротопією.

Гетеротопія здатна показати соціальні і інформаційні взаємодії між людьми, іiї аналіз відкриває можливість детальнішого вивчення місцезнаходжень в культурному та соціальному 
просторах, тобто гетеротопія - це простір, який відображає культурну, політичну, соціальну, мистецьку взаємодію, та структурує суспільство за допомогою образів.

Результати. В своїй концепції М.Фуко розглядає так звані «утопії» - простори, в яких може реалізуватися ідеальний суспільний порядок, ірреальні структури, що підтримують загальний зв'язок із реальним соціальним простором (наприклад, ідеальне місто, здатне задовольнити соціальні, культурні, політичні, естетичні та ін. потреби його жителів). Гетеротопії вважаються контр-місцями стосовно утопії, місцями, передбаченими суспільним інститутом, а саме: «утопіями, в яких реальні простори, усі реальні розміщення, що належать культурі, водночас репрезентуються, заперечуються та перевертаються; такі місця, що перебувають поза усіма місцями, попри те, що їх справді можна локалізувати» (Міщенко, Штретлінг 2018). Під гетеротопією М.Фуко розуміє простір, що знаходиться за межами інших, і в якому не діють звичні для суб'єкта норми та закони, поведінкові стереотипи зазнають значних змін. Людина, що потрапляє у гетеротопію, змушена пристосовуватись до нових умов i, так чи інакше, здійснювати акт трансгресії, тобто переступати за рамки традиційної поведінки. М.Фуко класифікував весь спектр міських просторів, які певним чином виділяються із загальної міської картини. По-перше, це гетеротопії кризи - певні місця, орієнтовані на людей, що знаходяться у кризовому стані відносно соціуму, в якому вони перебувають (наприклад, літні люди, підлітки і т.д.); по-друге, це гетеротопї̈ девіащіï, до яких відносять простори для людей, чия поведінка вважається девіантною стосовно загальноприйнятої. Третім типом гетеротопій, який М.Фуко не окреслив настільки чітко, як два попередні, $\epsilon$ гетеротопії ілюзії, в яких поєднується матеріальне і нематеріальне, вигадане і реальне - музеї, кінотеатри, розважальні центри тощо. Цей тип гетеротопії $\epsilon$ характерною рисою кінця індустріальної епохи і неодмінним атрибутом постіндустріального суспільства.

У визначенні гетеротопії М.Фуко виділяє декілька принципів. По перше, гетеротопії створюються всюди та можуть набувати різних форм. Це явище є універсальним. По-друге, гетеротопія підлаштовується під домінуючі тенденції культури, в часових рамках яких вона перебуває. Цікавим прикладом є гетеротопія кладовища: спершу цвинтарі знаходились у центральній частині агломерацій та існувало певне різноманіття способів поховань (персональні могили, оссуарії). Згодом, з настанням епохи віри у безсмертя душі, тілу надавали більш важливого значення, адже воно вважалось унікальним слідом існування людини. Починаючи з XIX сторіччя, поховання перенесли за межі міст, адже змінилося сприйняття смерті: це явище асоціювалося 3 недугою, а кладовища вважали «зонами зараження». По-третє, гетеротопія - зв'язний елемент між несумісними просторами (наприклад, театр, що «поєднує у периметрі сцени цілу низку взаємно розбіжних місць», або «прямокутна зала кінотеатру, в глибині якої на двовимірному екрані проектується тривимірний простір» (Міщенко, Штретлінг 2018). По-четверте, гетеротопії $є$ місцями накопичення та плинності часу (прикладом гетеротопії простору накопичення часу $\epsilon$ бібліотека або музей; до гетеротопій скороминущих можна віднести виставкові площі, центри сучасного мистецтва. По-п'яте, гетеротопії завжди ізольовані, але водночас доступні (у такі простори можуть потрапити усі, але туди буває непросто увійти: лише через примус (казарми чи в'язниці), або виконавши певний ритуал (купивши квиток чи зареєструвавшись на мистецьку подію). По-шосте, гетеротопія виконує окрему функцію відносно решти простору: «створення простору ілюзії, що викриває іще більшу ілюзорність будь-якого реального простору...» (Foucault, 1994).

Якщо розглядати сучасні тенденції розвитку міських суспільних мистецьких просторів, то виставкові павільйони та мистецькі центри як приклади гетеротопії ілюзії, поступились сьогодні арт-кластерам - ревіталізованим промисловим спорудам, пристосованим до функціонування різноманітних мистецьких практик. Арт кластер - це культурне об'єднання, розташоване на території колишньої промислової зони, яке містить у собі виставковий простір, театральну та кіно-площадку, аудиторії для семінарів, фуд-корти та інші схожі елементи. Арт-кластери або «Лофти» є найбільш розповсюдженими формами організації креативних просторів на території колишніх заводів та фабрик. Промислові зони з часом 
припиняли своє функціонування, і ставали місцями зосередження представників творчих професій, неформальних організацій та представників різноманітних девіантних культур. Кластери можна вважати позитивними просторами, адже арт-кластери як синтетичне явище поєднують в собі як вільний творчий пошук художників, так і вирішення соціальних завдань. Ревіталізований простір створюється як місце, спрямоване в майбутнє: тут сучасне мистецтво знаходить свою територію і освоює новий індустріальний масштаб. Сьогодні в багатьох сучасних містах арт-кластери як типи суспільних просторів стають одними з важелів впливу, здатними вирішити культурно-мистецькі та соціальні проблеми (Казакова, 2017).

Але, з іншого боку, у цьому контексті метафора «ревіталізації» натякає на мертве тіло, яке оживлюють. Деякі критики стверджують, що простір, створений під гаслом ревіталізації, насправді виявляє ознаки девіталізації (Міщенко, Штретлінг 2018). «Зрештою багато будівель розверталися спиною до вулиці або переобладнувалися для комерційної діяльності, чим сприяли приватній політиці виключення» (Kelley, Davis, 1990). Тому, деякі мистецькі простори можна віднести також і до гетеротопій кризи.

Слід звернути увагу на те, що мистецтво часто є явищем девіантним, але все-таки, існує мистецтво більш пристосоване до сприйняття пануючою культурою, та тотально-незалежне мистецтво, що не підлаштовується під загальноприйняте, як-от сквотерський митецький рух.

Сквотинг - це процес самовільного заселення покинутих чи нежитлових приміщень людьми, що не $є$ орендарями чи юридичними власниками цієї нерухомості. Сквотинг розвивається саме у промислових містах великих розмірів та має багато різних напрямків (Школяр, 2019). За класифікацією голландського соціолога Г. Прайта, одним із типів сквотингу є «соціально-культурний центр» - це може бути бар, воркшоп-зона, мистецька студія, ресторан, арт-галерея, духовний центр тощо. У цьому випадку покинуті будинки стають сквотами, щоб уникнути серйозних фінансових вкладень та бюрократичних процедур (Общее дело, 2015). Багато з таких сквотів згодом можуть отримати легальний статус, однак першочергово формуються фактично нелегально, 3 порушенням суспільних правил. Такі новостворені мистецькі суспільні простори можна трактувати як приклад гетеротопії девіації. У більшості випадків соціокультурною домінантою існування сквоту $є$ розвиток у його просторі творчої ініціативи активістів, що у подальшому призводить до формування нових культурних (часто контркультурних) просторів у межах діяльності сквотерської течії. Взагалі, творчість в маргінальних просторах може бути досить різнобічною, вона проходить шлях від експозицій в рамках традиційної культури до сучасних форм мистецтва. Сквоти виникають як центри, що об'єднують різноманітні культурні сфери (Школяр, 2019).

Крім зазначеного типу сквотингу, Г.Прайд також говорить про такі типи, як, наприклад, «альтернативна незалежна житлова стратегія»: люди, які не хочуть працювати для оплати квартирної ренти та мають бажання жити в групі, створюють власний житловий простір, який дає можливість долучитися до певного стилю життя (наприклад, панки можуть підселитися до панків, феміністки можуть утворити жіночу комуну і т.д). На нашу думку, використовуючи термінологію М.Фуко, сквотинг «як альтернативна житлова стратегія» може трактуватись як своєрідна реалізація утопії - певна спроба створити власну модель «ідеального простору», однак часто це суперечить загальним суспільним правилам. Тому ця «утопія» в реальному житті перетворюється на гетеротопію девіації. Втіленням гетеротопії кризи можна вважати «вимушений» (бездомні, іммігранти, переселенці, які займають покинуті будівлі), «консерваційний» (незаконне захоплення будівлі 3 метою протидії знесенню чи нераціональному використанню будівель) та «політичний» типи сквотингу за Г Прайдом (платформа для тих, хто веде боротьбу проти системи і нерідко перебуває в опозиції до представників інших форм сквотерів;) тощо (Школяр, 2019).

Висновки. Можемо зробити висновок, що місця концентрації сучасного мистецтва, які ми розглядали на прикладі арт-кластерів, за М.Фуко є позитивними просторами плинності часу, або ж, іншими словами, - гетеротопіями нетривких властивостей часу, де розробляється альтернативне майбутнє. Якщо ж розглядати девіантні мистецькі утворення, такі як артсквоти, через призму теорії гетеротопії, то їх можна віднести до гетеротопій девіації, адже, у 
більшості випадків, такі утворення є місцями концентрації представників маргінальних мистецьких практик. Слід також зауважити, що арт-майданчики в сучасну епоху діджиталізації є гетеротопіями ілюзії, адже з появою нових форм візуального мистецтва, зокрема, медіа-арту, такі простори стають просторами віртуальної реальності.

\section{References:}

Zhulkevskaya OV, Grishchenko MV (2012). The public space of the city as an object of sociological study and the empirical referent of social change. Methodology of Sociological Research, No. 1, Section 2, 61-66

The common thing: how squatting came about, what it is like and why is still relevant again. Furfur (2015). URL: http://www.furfur.me/furfur/culture/culture/179301- squat? Fbclid = IwAR3jvMvYJVVpupWiIqAz7WjK792JtlMrxQI63BSjpYV6R5CGO5eH7wWTjA

Moving space. Interdisciplinary Anthology (2018). Kiev: Art Book LLC

Kazakova K. (2017) Contemporary art in the structure of the art cluster: development potential and forms of interaction. (Dis. Candidate of Art History). Yekaterinburg.

Foucault M., (2006). Other spaces. Intellectuals and Power: Selected Political Articles, Speeches, and Interviews. M: Praxis. Part 3. 191-204.

Shkoliar S. (2019). Squatting as a mechanism for the development of contemporary art and cultural industries. Sociology - Social Work and Social Security - Regulation of Social Problems, Proceedings of the IX International Scientific Conference. May 16-17, 2019 - Lviv. 83-86.

Foucault M. (1994) Dits et Ecrits 1954-1988 - IV 1980-1988. Des Espaces autres.- Paris: Gallimard. Kelley Robin D.G. (1997) Yo Mama`s Dysfuncational. Fighting the Culture Wars in Urban America. Beacon Press: Boston

\section{Список використаних джерел:}

Жулькевська О.В., Грищенко М.В (2012). Суспільний простір міста як об'єкт соціологічного вивчення та емпіричний референт соціальних змін. Методологія соціологічних досліджень, №1, Розділ 2, 61-66

Общее дело: как появился сквотинг, каким он бывает и почему снова актуален сейчас Фурфур. (2015). URL: http://www.furfur.me/furfur/culture/culture/179301squat?fbclid=IwAR3jvMvYJVVpupWiIqAz7WjK792JtlMrxQI63BSjpYV6R5CGO5eH7w WTjA

Рухливий простір. Міждисциплінарна антологія (2018). Київ: ТОВ «Арт книга»

Казакова К. (2017) Современное искусство в структуре арт-кластера: потенциал развития и формы взаимодействия. (Дис. канд. истории искусств). Екатеринбург.

Фуко М., (2006). Другие пространства. Интеллектуальы и власть: Избранные политические статьи, выступления и интервью. М: Праксис. Ч.3. 191-204.

Школяр С.Р. (2019). Сквотинг як механізм розвитку сучасного мистецтва та культурних індустрій. Сочіологія - сочіальна робота та соиіальне забезпечення - регулювання соціальних проблем, Матеріали IX Міжнародної наукової конференції. 16-17 травня 2019 року. - Львів. 83-86.

Foucault M.(1994) Dits et Ecrits 1954-1988 - IV 1980-1988. Des Espaces autres.- Paris: Gallimard. Kelley Robin D.G. (1997) Yo Mama`s Dysfuncational. Fighting the Culture Wars in Urban America. Beacon Press: Boston

\section{Contact information :}

Школяр Софія schtcho@gmail.com

Школяр Мар'яна

shkolyar.maryana@gmail.com 